Otterbein University

Digital Commons @ Otterbein

Health and Sport Sciences Faculty Scholarship

Health and Sport Sciences

2008

\title{
Understanding Leadership Skills of Hospice Executives
}

Paul D. Longenecker

Otterbein University

Follow this and additional works at: https://digitalcommons.otterbein.edu/hsports_fac

Part of the Health and Medical Administration Commons

\section{Repository Citation}

Longenecker, Paul D., "Understanding Leadership Skills of Hospice Executives" (2008). Health and Sport Sciences Faculty Scholarship. 3.

https://digitalcommons.otterbein.edu/hsports_fac/3

This Article is brought to you for free and open access by the Health and Sport Sciences at Digital Commons @ Otterbein. It has been accepted for inclusion in Health and Sport Sciences Faculty Scholarship by an authorized administrator of Digital Commons @ Otterbein. For more information, please contact

digitalcommons07@otterbein.edu. 


\section{UNDERSTAN D IN G \\ LEADERSHIP SKILLS OF HOSPICE EXECUTIVES}

\section{PAUL LONGENECKER}

The healthcare industry is a rapidly changing environment requiring leaders to possess a high level of leadership skills. Leaders in the hospice industry have experienced the same level of change, but over the brief span of 25 years. With the aging of hospice executives and the dynamic environment of the hospice industry, the need for strong leadership is more important than ever. This research study reports on the perceived leadership skills of hospice executives and is a replication of an earlier study (Longenecker, 2006). All study participants were executives of organizations that participated in clinical and operational benchmarking activities at the national level. The study evaluated leadership skills using transformational leadership theory as the conceptual model by which leadership skills were measured. The results of the study identified that the participants perceived they displayed an ideal use of skills based on transformational leadership theory.

\section{Introduction}

The healthcare industry is a rapidly changing environment requiring high levels of skill in its leaders. The changes that healthcare leaders must confront on a daily basis include increased costs related to advancing technology and personnel shortages, ongoing modifications in reimbursement rates from managed-care organizations, the impact of chronic disease on care delivery, and the aging of Americans. While change is not unique to the healthcare industry, few industries have confronted change that is occurring as rapidly and frequently as healthcare providers (Heinman, 2000; McConnell, 2000). These changes in healthcare are magnified when looking at hospice care. Hospice providers have "witnessed these changes over the brief span of
25 years" (Longenecker, 2006, p. 205). To quantify the significance of the changes in hospice care, the number of individuals cared for annually by hospice providers has grown from 150,000 in 1985 to 1.2 million in 2005, an $800 \%$ increase (National Hospice and Palliative Care Organization [NHPCO], 2006).

In addition to the changes confronted by all healthcare leaders, hospice leaders have needed to address additional issues unique to their industry. Besides the growth in the number of patients, hospice leaders are confronted with issues of internal and external competition to the industry, increased regulatory scrutiny, and increased discussion on ethical issues like physician-assisted suicide. Whereas these issues impact the operational side of hospice care, a significant 
challenge confronting the hospice industry, directly related to its leadership, is the aging of hospice executives.

As identified by recent studies, more than $50 \%$ of all hospice executives are over the age of 50 , with $10-15 \%$ over the age of 60 (Longenecker, 2006; NHPCO \& Furst, 2005). The term changing of the guard is being used within the industry for the transitioning of leadership (Longenecker, 2005). This evolutionary event poses the following question for consideration: Is the next wave of leaders ready to take over? To answer the question adequately, several key issues need to be evaluated. One, what leadership skills will be needed by hospice leaders in the future? Two, do hospice providers currently have succession plans in place? Three, what are the leadership skills of current hospice leaders?

The focus of the research study was to explore the third issue: What are the leadership skills of current hospice leaders? The study was a replication of a previous study (Longenecker, 2006). Transformational leadership theory was utilized as the conceptual model by which leadership skills were measured.

\section{Review of the Literature}

\section{TRANSFORMATIONAL LEADERSHIP THEORY}

Transformational leadership was first defined by James MacGregor Burns in 1978 and was formalized into a theory including models and measurements tools in 1985 by Bass and Avolio. Bass and Avolio reported that the latest version of the measurement tool "has been used in nearly 300 research programs, doctoral dissertations and master's theses . . between 1995 and 2004" (Bass \& Avolio, 2004, p. 35).

Transformational leadership theory, also referred to as the "full-range leadership model," is composed of three main components: transformational leadership, transactional leadership, and laissez faire. The three aspects of the model represent differing approaches, styles, and beliefs about leading others.

The first component, transformational leadership, is based on the four Is: idealized influence (II), where leaders serve as role models for subordinates; individual consideration (IC), where leaders view each subordinate as being unique and work to connect with them as individuals; intellectual stimulation (IS), where leaders strive to maximize creativity and new ideas; and inspirational motivation (IM), where leaders work to creare team spirit and meaning in their subordinates' work.

The second component, transactional leadership, is based on exchanges that occur berween the leader and subordinate and is divided into two areas. The first area, contingent reward (CR), is based on positive feedback. If the subordinate does a designated task, he or she is rewarded. If the task is nor completed, no reward is given. The second area is management-by-exception (MBE), and is based on negative feedback. Only when errors are found is feedback given and the feedback focuses on punitive action.

The last area is lassiez faire, which is defined as nonleadership. The ideal leader uses all three types of behavior, but utilizes transformational leadership techniques the most frequently and laissez faire the least.

The key attribute of transformational leadership theory is its "emphasis on development" (Bass \& Avolio, 2004, p. 4). Leaders who utilize only transactional leadership or management techniques will not be able to facilitate the growth of their organization, deal with the competitive nature of today's work environment, or maximize the potential of their workforce (Bass \& Avolio). To create an environment that deals well with change, the leader must identify ways to empower followers to be involved and committed to the organization.

\section{PRIOR RESEARCH FINDINGS}

Although transformational leadership theory has been used extensively in leadership research, its use in healthcare settings has focused primarily on acute care settings and the evaluation of nursing leadership. Only one prior study was found that evaluated leadership skills of hospice executives.

In scudies conducted in hospital settings focused on executive-level personnel, strong correlations were found between transformational leadership skills and satisfaction of personnel and outcome criteria (Dixon, 1997; Lawrence, 2000; Spinelli, 2004). In a study by Arends (1997), evaluating borh junior and senior administrators in Air Force healthcare settings, significant correlation was found between all - seven leadership styles and outcome criteria based on perception of subordinates. In studies evaluating nursing leadership, similar correlations were found between job satisfaction and transformational leadership (Ramey, 2002) and among leadership and type and degree of commitment experienced by staff nurses (Leach, 2005). Two additional studies were identified that evaluated transformational leadership in social workers and respiratory therapists (Mary, 2005; Parkman, 2001). Both studies found a correlation between transformational leadership and ourcome variables.

In my prior study evaluating leadership skills of hospice executives, several key findings were reported (Longenecker, 
2006). The study was conducted on hospice executives in the State of Ohio using the Multifactor Leadership Questionnaire (MLQ) 5X Leadership Form (Bass \& Avolio, 2004) to evaluate the components of transformational leadership theory. The study was descriptive, using a self-report technique and a purposive sampling approach. In addition to the MLQ tool, demographic data were collected on the participants and their organizations. The study sample represented approximately $1 \%$ of hospice executives in the U.S. In the study, the participants reported self scores that mirrored the ideal full-range leadership model. However, the key finding of the study identified several statistically significant correlations that were contrary to the ideal full-range leadership model.

Years of hospice experience (YHE) was identified to have statistically significant correlations in three areas. One, as YHE increased, use of laissez faire increased, use of individual consideration decreased, and management-by-exception (passive) increased (Longenecker, 2006). "All three tendencies identified appear to demonstrate a lower level of urilization of strong transformational leadership skills as YHE increased" (Longenecker, p. 210). It was reported that these findings could indicate several patterns: one, increased comfort with nontransaction; two, a lack of willingness to get involved in resolving issues; and three, the possibility of burnout related to length of time involved in hospice care (Longenecker). Further investigation of the transformational leadership skills of hospice executives was recommended.

\section{Method}

The research reported here was a replication of the Longenecker study (2006). A descriptive survey approach using questionnaires was utilized. The research sample was a convenience sample focused on gathering data from hospice executives from across the U.S. The study explored two hypotheses: (a) perceived transformational leadership skills of hospice executives in other states is similar to those of hospice executives in Ohio, and (b) increased experience in hospice care is not an indicator of strong transformational leadership skills. The study was conducted in conjunction with Perforum, an organization that specializes in hospice benchmarking and performance improvement. Perforum was selected for involvement in the study based on its association with a variety of hospices across the United States.

Data were gathered using an online/Web-based survey. The collection tool consisted of three sections. The first was the Multifactor Leadership Questionnaire (MLQ) 5X Leadership
Form, a tool developed by Bass and Avolio to gather information based on the components of transformational leadership theory (2004). The MLQ consists of 45 questions using a Likert scale. The second, a personal demographic questionnaire, gathered data on the participant's job title, area of specialization, level of education, years of leadership and hospice experience, age, and gender. The third tool was an organizational demographic questionnaire that gathered data on the participant's organization including state of origin, agency type, profit status, service area, annual budget, average daily census (range), actual average daily census (FY 2004), actual average length of stay (FY 2004), and annual median length of stay (FY 2004).

To initiate the data-collection process, an e-mail was sent to the hospice executives of Perforum-affiliated hospice organizations. The e-mail contained an invitation to participate in a hospice-leadership survey, an explanation of the study, and a link to the online survey. To gain access to the online survey, each participant was required to enter his or her Perforum agency ID and password. This process was intended to maintain confidentiality and allow only one survey per organization. Participants were given a 2-week deadline to complete the survey. All survey results were entered electronically into an Excel spreadsheet database by Perforum staff and forwarded to the researcher for analysis. A total of 88 individuals were invited to participate in the research study.

\section{Results}

The analysis was conducted using an Excel Analysis Toolpak. Descriptive statistics were used for demographic data and MLQ responses. Pearson product-correlation coefficient (Pearson $r$ ) analysis was utilized to examine relationships between leadership variables and personal and organizational demographic characteristics of participants. Analysis of variance (ANOVA) testing was urilized to evaluate relationships within groupings. An alpha level at the .05 level of significance was utilized for all statistical analysis.

Thirty-five hospice executives participated in the study, representing a $40 \%$ return rate. Only 28 participants completed the three questionnaires in their entirety. For purposes of analysis, only the questionnaires that were $100 \%$ complete were utilized. The 28 respondents represent less than $1 \%$ of hospice executives in the U.S. The demographic information on the participants and their organizations are described in Table 1. 


\section{Table 1. Personal and Organizational Demographic Characteristics}

\begin{tabular}{|c|c|c|c|c|c|}
\hline Personal characteristics & $n$ & $\%$ & Organizational characteristics & $n$ & $\%$ \\
\hline Job title & & & Agency type & & \\
\hline Executive director & 14 & 50 & Freestanding & 16 & 47.9 \\
\hline President/CEO & 6 & 21 & Hospital based & 6 & 21 \\
\hline Other & 5 & 18 & Home health & 4 & 14.3 \\
\hline Administrator & 2 & 7 & Other & 2 & : \\
\hline Branch manager & 1 & 3.5 & Profit status & & \\
\hline Area of specialization & & & Not-for-profit & 28 & 100 \\
\hline Nursing & 16 & 57 & For-profit & 0 & 0 \\
\hline Business & 5 & 18 & $\overline{\text { Service area }}$ & & \\
\hline Social work & 3 & 10.7 & Both rural and urban & 18 & 64.2 \\
\hline Other & 3 & 10.7 & Rural & 6 & 21 \\
\hline Bereavement & 1 & 3.5 & Urban & 4 & 14.3 \\
\hline Level of education & & & Annual budget & & \\
\hline Master's degree & 19 & 68 & $<.5$ million & 1 & 3.5 \\
\hline Bachelor's degree & 7 & 25 & $>.5$ million-1 million & 1 & 3.5 \\
\hline Associate's degree & 2 & 7 & $>1$ million-2 million & 4 & 14.3 \\
\hline Years of leadership experience & & & $>2$ million-3 million & 4 & 14.3 \\
\hline$<5$ & 1 & 3.5 & $>3$ million-5 million & 4 & 14.3 \\
\hline $6-10$ & 4 & 14.3 & $>5$ million & 14 & 50 \\
\hline $11-15$ & 10 & 357 & Average daily census (ADC) & & \\
\hline $16-20$ & 4 & 35.1 & $<25$ patients & 2 & 7 \\
\hline $21-25$ & 4 & 14.3 & $26-50$ & 6 & 21 \\
\hline $21-23$ & 4 & 14.3 & $51-100$ & 9 & 32.1 \\
\hline$>25$ & 5 & 18 & $101-250$ & 7 & 25 \\
\hline Years of hospice experience & & & $251-500$ & 2 & 7 \\
\hline$<5$ & 4 & 14.3 & $>500$ & 2 & 7 \\
\hline $6-10$ & 6 & 21 & Geographic region & & \\
\hline $11-15$ & 5 & 18 & Northeast & 11 & 39.3 \\
\hline $16-20$ & 8 & 28.5 & Great Lakes & 7 & 25 \\
\hline $21-25$ & 4 & 14.3 & Southeast & 5 & 17.8 \\
\hline$>25$ & 1 & 3.5 & Central Plains & 3 . & 10.7 \\
\hline Age & & & West & 2 & 7.1 \\
\hline$<30$ & 1 & 3.5 & & & \\
\hline $31-40$ & 1 & 3.5 & & & \\
\hline $41-50$ & 7 & 25 & & & \\
\hline $51-60$ & 16 & 57.9 & & & \\
\hline$>60$ & 3 & 10.7 & & & \\
\hline \multicolumn{6}{|l|}{ Gender } \\
\hline Female & 24 & 85 & & & \\
\hline Male & 6 & 15 & & & \\
\hline
\end{tabular}


The most common characteristics of the hospice executives were as follows:

Executive director: $50 \%$

Nursing specialization: $57 \%$

Possess master's degree: $68 \%$

$11-15$ years of leadership experience: $35.7 \%$

16-20 years of hospice experience: $28.5 \%$

$51-60$ years old: $57.9 \%$

Female: $85 \%$

The mean age of participants was 52.1 years with an $S D$ of 8.46. The median age was 53 , and the mode was 55 . The distribution appears to be slightly negatively skewed. The mean years of leadership experience (YLE) was 17.7 years with an $S D$ of 8.55 . The median and mode YLE were both 15 . The distribution appears to be slightly positively skewed. The mean years of hospice experience was 13.9 with an $S D$ of 7.39. The median YHE was 14 and the mode 20. The distribution appears to represent a normal curve.

The most common characteristics of participants' organizations were as follows:

Freestanding agency: $57.9 \%$

Nonprofit status: $100 \%$

Both rural and urban service areas: $64.2 \%$

Annual budget $>5$ million: $50 \%$

Average daily census (ADC) of 51-100 patients: 32.1

Northeast NHPCO Geographic Region: 39.3

The mean $A D C$ was 195.3 with an $S D$ of 418.85 . The median $A D C$ was 68 , and the mode was 110 with a range of 14-2200 patients. The mean average length of stay (ALOS) was 53.9 with a $S D$ of 19 . The median ALOS was 52.1 and a mode of 48 with a range of 16-100. The mean median length of stay (MLOS) was 17.75 with an $S D$ of 6.62 . The median and mode MLOS was 18 with a range of $6-36$.

The self-scores on the MLQ for the three main components of the full range of leadership model were transformational $=$ 3.46 , transactional $=1.84$, and laissez faire $=0.44$. The complete breakdown of the self-scores are identified in Table 2.

In evaluating the correlations among the three leadership styles, the eight individual leadership rechniques, and the personal and organizational characteristics, eight areas of statisti$\mathrm{cal}$ significance were identified. Five areas of significance were related to transactional leadership and its subcomponents,
Table 2. Self-Scores of Hospice Executives

\begin{tabular}{lll} 
Factor & Mean & SD \\
\hline Transformational leadership & 3.46 & 0.36 \\
Idealized influence (attributed) & 3.37 & 0.50 \\
Idealized influence (behavior) & 3.67 & 0.37 \\
Intellectual stimulation & 3.35 & 0.50 \\
Individualized consideration & 3.46 & 0.52 \\
Inspirational motivation & 3.44 & 0.42 \\
\hline Transactional leadership & 1.84 & 0.33 \\
Contingent reward & 3.14 & 0.45 \\
Management-by-exception (active) & 1.44 & 0.65 \\
Management-by-exception (passive) & 0.95 & 0.55 \\
\hline Laissez faire & 0.44 & 0.43 \\
\hline
\end{tabular}

while three areas were related to transformational leadership. No areas of statistical significance were identified for laissez faire; $p$ equaled .381 for all Pearson $r$ analyses. A complete summary of Pearson $r$ results can be found in Table 3 . Specific areas of statistical significance are shown in bold.

Using ANOVA to evaluate variance berween and among the components and subcomponents of the full-range leadership model and personal and organizational characteristics, six areas of statistical significance were identified. For YLE, IS had an $F$ value of 2.69 and MBE-A of 2.67. The $F$ critical value was 2.66. For YHE, MBE-A had an $F$ value of 2.785 . The $F$ critical value was 2.66 . For age, transactional leadership had an $F$ value of 4.36 with an $F$ critical value of 2.795 . For annual budget; transactional leadership had an $F$ value of 5.04 and MBE-P of 3.11. The $F$ critical value was 2.66 .

\section{Discussion}

The findings identified that hospice-executive participants reported the use of high levels of transformational leadership skills and mirrored the optimal usage pattern of leadership skills as defined by the full-range leadership model. The results are similar to findings from other studies on the model (Longenecker, 2006; Ohman, 2000) and findings from development and testing of the MLQ (Bass \& Avolio, 2004). In evaluating the specific personal characteristics of individuals that most closely mirrored the optimal usage pattern, it was found that for those with an associate's degree for highest level of education, 8 of 11 leadership skills matched the optimal 
Table 3. Pearson Product-Moment Correlation Coefficients of Leadership Styles

\begin{tabular}{|c|c|c|c|c|c|c|c|c|}
\hline \multirow[b]{2}{*}{ Characteristics } & & \multicolumn{7}{|c|}{ Leadership styles. } \\
\hline & & \multicolumn{2}{|c|}{ Transformational } & \multicolumn{3}{|c|}{ Transactional } & \multicolumn{2}{|r|}{ Laissez faire } \\
\hline Level of education & & \multicolumn{2}{|c|}{0.10} & \multicolumn{3}{|c|}{0.06} & \multicolumn{2}{|r|}{-0.08} \\
\hline Years of leadership experience & & \multicolumn{2}{|c|}{0.33} & \multicolumn{3}{|c|}{-0.34} & \multicolumn{2}{|r|}{-0.02} \\
\hline Years of hospice experience & & \multicolumn{2}{|c|}{0.31} & \multicolumn{3}{|c|}{$-0.44^{*}$} & \multicolumn{2}{|r|}{-0.27} \\
\hline Age & & \multicolumn{2}{|c|}{0.13} & \multicolumn{3}{|c|}{-0.41} & \multicolumn{2}{|r|}{-0.18} \\
\hline Annual budget & & \multicolumn{2}{|c|}{0.19} & \multicolumn{3}{|c|}{-0.39} & \multicolumn{2}{|r|}{0.27} \\
\hline Average daily census & & \multicolumn{2}{|c|}{0.11} & \multicolumn{3}{|c|}{-0.03} & \multicolumn{2}{|r|}{0.28} \\
\hline \multicolumn{2}{|l|}{ Average length of stay } & \multicolumn{2}{|c|}{0.42} & \multicolumn{3}{|c|}{-0.06} & \multicolumn{2}{|r|}{0.06} \\
\hline & \multicolumn{8}{|c|}{ Leadership techniques } \\
\hline Characteristics & II-A & H-B & is & IM & IC & CR & MBE-A & MBE-P \\
\hline Level of education & 0.15 & 0.06 & 0.05 & 0.01 & 0.25 & -0.12 & 0.23 & -0.06 \\
\hline Years of leadership experience & 0.38 & 0.23 & 0.20 & 0.21 & 0.25 & -0.001 & -0.40 & -0.14 \\
\hline Years of hospice experience & 0.14 & 0.24 & 0.19 & 0.28 & 0.36 & 0.06 & -0.42 & -0.33 \\
\hline Age & 0.28 & 0.13 & 0.04 & 0.03 & 0.009 & -0.02 & -0.34 & -0.30 \\
\hline Annual budget & 0.29 & 0.006 & 0.31 & -0.07 & 0.19 & -0.24 & -0.235 & -0.02 \\
\hline Average daily census & 0.29 & 0.15 & -0.045 & -0.05 & 0.10 & -0.16 & 0.15 & -0.10 \\
\hline Average length of stay & 0.40 & 0.34 & 0.37 & 0.17 & 0.365 & -0.08 & 0.06 & -0.11 \\
\hline
\end{tabular}

Note: $p=381$ for all Pearson $r$ analysis. "Pearson $r$ results were statistically significant at alpha level of $0.05(p .<.05)$. II-A = idealized influence-attributed $\mathrm{H}-\mathrm{B}=$ idealized influence-behavior; $I S=$ intellectual stimulation; $I M=$ inspirational motivation; $I C=$ individualized consideration; $C R=$ contingent reward; $M B E-A=$ management-by-exception (active); MBE-P = management-by-exception (passive).

pattern, and among females in the sample, 9 of 11 matched the optimal leadership skills pattern. In evaluating the portion of the sample these two segments represented, associate's degree holders represented $7 \%$ and females represented $85 \%$ of the sample. Based on percentages, female gender would appear to be a better predictor of the optimal pattern. In addition, transformational leadership and its four subcomponents had higher scores than transactional leadership and its three subcomponents, which had higher scores than laissez faire.

In comparing the demographic data, the personal characteristics closely mirror findings from other studies and sources (Longenecker, 2006; NHPCO \& Furst, 2005; Perforum, 2005). All three sources identified the most common results as executive director for job title, nursing for area of specialization, master's degree for highest level of education, and female for gender. For YLE, YHE, and age, the previous studies had varying results; however, when evaluating the mean for these three categories, the results were very similar (Longenecker, 2006;
NHPCO \& Furst). The findings strongly support the pattern identified in the changing-of-the-guard phenomenon of an aging population of hospice executives with extensive hospice experience (Longenecker, 2006).

In comparing organizational demographics from the studies, similar patterns of commonality were found. In all three studies, the most common results were freestanding for agency type, not-for-profit for profit status, and both rural and urban for service area. In comparing ALOS and MLOS results, the results were similar to those in the previous study (Longenecker, 2006). In evaluating the budget size of participants' organizations, the current study had a larger number of hospice agencies $(50 \%)$ with budgets over five million. Hospice agencies of this size in the NHPCO and Furst (2005) and Longenecker (2005) studies represented approximately $33-35 \%$ of the participants. These comparisons seem to represent a high level of similarity among participants' organizations in the three studies. A unique finding 
of the study was the high percentage of not-for-profit organizations involved. Nor-for-profit organizations represented $100 \%$ of the sample as compared to the $85 \%$ reported by NHPCO and Furst. In evaluating the makeup of Perforum membership, nonprofits represent $98 \%$ (Perforum, 2005), which would appear to explain this.

The self-scores reported mirrored the optimal usage pattern identified by previous research (Bass \& Avolio, 2004; Longenecker, 2006). The only difference found in comparing studies was in adherence to the optimal pattern. The pattern was more prominent in the current study with transformational leadership and its subcomponents scores being consistently higher and transactional leadership and laissez-faire scores being consistently lower.

In evaluating the results of the Pearson $r$ analysis, the findings demonstrated a consistent pattern of statistically significant findings that mirrored the ideal usage partern of full-range leadership theory. For transformational leadership (TFL), three areas of statistically significant findings showed weak to moderate positive correlations. Specifically, as ALOS increased, use of TFL and idealized influence-attributed (II-A) increased, and as YLE increased, use of II-A increased. For transactional leadership (TAL), five areas of statistically significant findings showed weak to moderate negative correlations. Specifically, as YLE increased, management-by-exception (active) (MBE-A) decreased; as YHE increased, use of TAL and MBE-A decreased; as age increased, use of TAL decreased; and as annual budget increased, use of TAL decreased. These findings would appear to signify that as hospice execurives age and gain experience in both leadership and hospice, their use of transformational leadership skills increased and use of transactional leadership skills decreased. From an organizational perspective, the findings would appear to signify that as organizations grow in size and number of patients served, and as their patients receive care for longer periods, leaders increased use of TFL skills and decreased use of TAL skills.

Enhancing the significance of these findings were the results of the ANOVA analysis. Of the six statistically significant ANOVA findings, five areas involved relationships within and between groupings and pertained to transactional leadership and its subcomponents. The relationship between TAL, age, and annual budget groupings suggested that the differences were not due to chance. Similarly, the relationship between TAL and MBE-P, and YLE, YHE, and MBE-A, were also not due to chance. In addition, four of the six statistically significant ANOVA findings corresponded with the Pearson $r$ results. These findings validate that TAL, age, and annual budget, and MBE-A, YLE, and YHE, are significantly related as predictors of full-range leadership theory behaviors.

These overall findings, although limited in the overall scope of the study, appear to be significant in that they contradict previous research findings (Longenecker, 2006). In the prior study, the pattern found was opposite to the optimal usage of leadership skills based on the full-range leadership model. As YHE increased, use of laissez faire (LF) increased, individualized consideration (IC) decreased, and MBE-P increased (Longenecker). These conflicting results raise the following question: Why are the findings from these studies in direct contrast to each other?

In reviewing the sample populations of the studies, no significant differences are apparent. Demographically, the participants in both studies hold similar job titles, areas of specialization, levels of education, years of leadership and hospice experience, and age. In addition, their organizations have similar characteristics, including profit status, budget sizes, ADC, ALOS, and MLOS.

The only notable differences between the samples were where the respondents lived in the United States and the fact that the participants in the current study were execurives of organizations that participated in national benchmarking. In exploring these differences, the first study's participants were from the state of Ohio whereas the second study's participants were from different states. While this may explain the variance between the groups in the studies, the similarities between the groups when comparing the personal and organizational demographics would appear to make this difference less significant.

The second difference noted would appear to represent a more valid reason for the contrasting findings. The hospice executives in the current study were from organizations that benchmarked performance-improvement data, both clinical and operational, with other hospice organizations across the United States (Perforum, 2005). Participation in the benchmarking process through Perforum is an elecrive process and not required of hospices.

Based on the characteristics of a transformational leader, exposing one's organization to comparison to and scrutiny by other hospices across the country would appear to represent a high level of transformational leadership skills. This is demonstrated by (a) role modeling (idealized influence) by setting a high standard, (b) motivating others (inspirational motivation) through setting a vision of excellence, (c) looking at new ways to improve performance (intellectual stimulation), and 
(d) creating an environment to recognize the achievements of personnel and maximize their potential (individual consideration) through their expanded experience. Involvement of an organization in benchmarking at a high level would appear to demonstrate a significant commitment to maximizing the potential of the leader, their followers, the organization, and the services provided. However, although a hospice executive whose organization is involved in interorganizational benchmarking may be displaying characteristics of a transformational leader, the sole act of involvement in benchmarking does not make the individual a transformational leader. The intent behind the action would be the driving force of demonstrating transformational leadership skills.

Neither hypothesis was supported. Hospice executives from other states did appear to display a different level of transformational leadership skills than executives in Ohio. Also, in certain areas (TAL skills and MBE-A), years of hospice experience were staristically significant in representing the optimal profile of the full-range model of leadership.

Numerous limitations were identified that could impact the applicability of the findings to a broader population. These limitations were (a) small sample size; (b) diverse makeup of the sample; (c) the MLQ being used as a self-reporting tool, resulting in findings representing an individual's perception of their own leadership skills; (d) the survey requiring an understanding of, use of, and access to the Internet; and (e) the topic and prior research study findings had been presented to hospice leaders at state and national conferences in the past.

An additional point of reference in evaluating the findings was that the hospices asked to participate were not selected based on their benchmarking practices but their diverse geographic locations. The discovery of benchmarking being a significant variable in the findings was an unforeseen result.

\section{Conclusion}

Based on the findings from the two studies, further evaluation of leadership skills of hospice leaders is needed. A key area for follow-up is in the area of benchmarking. To validate the findings of the study, additional investigation is needed to support this as an indicator of displaying transformational leadership skills. An additional area of focus would be the completion of research using both the leader and rater forms of the MLQ to compare the perception of hospice executives' leadership skills with the perception of their subordinates.
Both studies on leadership skills of hospice executives identified that executives perceived that they used skills reflective of the optimal pattern of full-range leadership theory. Additionally, a larger sample size would help in improving the applicability of the findings to the general population of hospice executives.

\section{References}

Arends, J. A. (1997). Transactional, transformational, and laissezfaire leadership styles of the senior administrator and junior administrators in Department of the Air Force medical treatment facilities (Doctoral dissertation, Nova Southeastern University). Dissertation Abstracts International B, 57/12, 7434.

Bass, B., \& Avolio, B. (2004). Multifactor Leadership Questionnaire Manual and Sampler Set (3rd ed.). Redwood City, CA: Mindgarden.

Dixon, D. L. (1997). The relationship between chief executive leadership (transactional and transformational) and hospital effectiveness (Doctoral dissertation, The George Washington University) Dissertation Abstracts International A, 58/05, 1808.

Heinman, E. A. (2000). Leadership profiles of senior nurse executives. Canadian Journal of Nursing Leadership, 13(1), 21-30.

Lawrence, E. T. (2000). The relationship between transformational, transactional, and laissez-faire leadership styles of the senior executives/department heads and their immediate subordinates' perceived satisfaction, extra effort, effectiveness, and organizational culture typology in the hospital settings (Doctoral dissertation, Nova Southeastern University). Dissertation Abstracts International $A, 61 / 02,660$.

Leach, L. S. (2005). Nurse executive transformational leadership and organizational commitment. Journal of Nursing Administration, $35(5), 228-237$.

Longenecker, P. (2005, September). The changing of the guard: The future of hospice leadership. Paper presented at the National Hospice and Palliative Care Organization (NHPCO) 20th Management and Leadership Conference, Hollywood, FL.

Longenecker, P. (2006). Evaluating transformational leadership skills of hospice executives. American Journal of Hospice \& Palliative Medicine, 23(3), 205-211.

Mary, N. L. (2005). Transformational leadership in human service organizations. Administration in Social Work, 29(2) 105-118.

McConnell, C. R. (2000). The changing face of health care management. Health Care Manager, 18(3), 1-17.

National Hospice and Palliative Care Organization (2005). Hospice Facts and Figures. Alexandria, VA: Author.

National Hospice and Palliative Care Organization (2006). 2006 in Review. Alexandria, VA: Author. 
National Hospice and Palliative Care Organization \& Furst Group (2005). 2005 Hospice and Palliative Care Leadership Survey. Rockford, IL: Furst Group.

Ohman, K. A. (2000). The transformational leadership of critical care nurse-managers. Dimensions in Critical Care Nursing, 19(1), 46-53.

Parkman, A. (2001). An investigation of Bass' model of transformational and transactional leadership theory in respiratory care (Doctoral dissertation, Capella University). Dissertation Abstracts International $A, 62 / 02,671$.

Perforum (2005). Agency Profile Table. Lyme, NH: Perforum.

Ramey, J. W. (2002). The relationship between leadership styles of nurse managers and staff nurse job satisfaction in hospital sertings. (Master's thesis, Marshall University). Masters Abstracts International, 42/04, 1244.

Spinelli, R. J. (2004). Transformational, transactional, and laissezfaire leadership: An investigation of Bass's (1985) theory in the hospital administrative environment. (Doctoral dissertation, Nova Southeastern University). Dissertation Abstracts International B, $65 / 08,3933$.

Paul D. Longenecker is an Assistant Professor of Leadership Studies in the School of Professional Studies at Lourdes College. He teaches in the Master of Organizational Leadership program with his areas of focus being leadership theory, organizational behavior, and ethical practice. In addition to his academic role, he is the President and Lead Consultant for The Transformational Group, LLC, where he provides consulting services on leadership and organizational practices. The focus of his research is leadership and organizational practices of hospice organizations. He holds both associate and bachelor degrees in Nursing, a master's degree in Health Care Administration and Management, and a Ph.D. in Health Administration. He can be reached at plongenecker@lourdes.edu. 